\title{
PALEOMAGNETISM OF SOME GONDWANA RED BEDS FROM CENTRAL INDIA
}

H. WENSINK

Geological Institute, State University, Utrecht (The Netherlands)

(Received July 2, 1968)

(Resubmitted October 30, 1968)

\section{SUMMARY}

Oriented samples were collected for paleomagnetic research from red horizons of the Gondwana sediments at a few localities in central India. The specimens were subjected to both alternating-field and thermal demagnetization and were measured on astatic magnetometers. Usually a stable direction of magnetization was observed only after thermal treatment.

The following results were obtained:

(I) The Upper Permian Kamthi Beds reveal a mean direction of magnetization given by $D=79.4^{\circ}, I=+61.6^{\circ}$ (pole position $21.05^{\circ} \mathrm{S} 50.4^{\circ} \mathrm{W}$; dp $=$ $2.8^{\circ}$ and $\mathrm{dm}=3.7^{\circ}$ );

(2) The Lower Triassic Mangli Beds have $D=100.1^{\circ}, I=+62.8^{\circ}$ (pole position $7.3^{\circ} \mathrm{S} 55.7^{\circ} \mathrm{W} ; \mathrm{dp}=5.7^{\circ}$ and $\mathrm{dm}=7.3^{\circ}$ );

(3) The Upper Triassic Pachmarhi Beds have $D=117.2^{\circ}, I=+48.9^{\circ}$ (pole position $10.15^{\circ} \mathrm{N} 49.9^{\circ} \mathrm{W}$; $\mathrm{dp}=4.0^{\circ}$ and $\mathrm{dm}=6.1^{\circ}$ ).

These results combined with earlier data indicate that the Indian subcontinent has made a sinistral rotation of about $90^{\circ}$ during Upper Paleozoic through Mesozoic times, without a considerable meridional shift.

\section{INTRODUCTION}

The present study deals with the paleomagnetism of rock samples from the Indian Gondwana sediments, collected during a field trip in the winter season of 1966-1967.

The Indian subcontinent is considered to have formed part of the Gondwana continents of the Southern Hemisphere, because of paleontological similarities.

Paleomagnetic studies on the Upper Cretaceous to Lower Eocene plateau basalts of the Deccan traps (Deutsch et al., 1959) as well as on the Jurassic Rajmahal traps (CLEGG et al., 1958) and Sylhet traps (ATHAVALE et a1., 1963) have demonstrated that during the Upper Mesozoic India was situated south of the equator. 
The paleomagnetic research is now extended to the, mainly Mesozoic, sediments of the Gondwana System (Verma et al., 1967, 1968). This paper presents some additional paleomagnetic data from the Gondwana sediments.

\section{GEOLOGICAL ASPECTS OF THE INDIAN PENINSULA}

The Indian peninsula consists of a basement of Precambrian metamorphic rocks and associated granitic intrusions belonging to the Dharwar System. Locally they are overlain by Late Precambrian sediments and volcanics of the Cuddapah and Vindhyan Systems. Rocks of a Lower Paleozoic age are not found on the Indian subcontinent.

The next stratigraphical unit is formed by a continental series which starts with glacial boulder beds and their associated peri-glacial beds of the Late Carboniferous glaciation. From that time onwards sedimentation continues through the greater part of the Mesozoic until the Lower Cretaceous. All these deposits are classified in the Gondwana System.

The rocks of the Gondwana System, which are chiefly composed of sandstones and shales, are almost entirely deposited in fresh water. Intercalations of coal measures occur; they are mainly found in the lower part of the system. The subdivision of the Gondwana System into two subsystems is based on the content of plants: the Lower Gondwana System is characterized by the Glossopteris flora; the younger Upper Gondwana System can be distinguished from it by a cycadaceous Ptilophyllum flora.

The transition between the Lower and the Upper Gondwana Systems takes place in the Upper Triassic. Apart from the subdivision into two separate systems advocated both by PASCOE (1959) and by KRISHNAN (1960), another subdivision is given by WADIA (1953) viz., into three systems. Wadia distinguishes the Lower, the Middle, and the Upper Gondwana Systems. These coincide with the Upper Carboniferous-Permian, the Triassic, and the Jurassic together with the Lower Cretaceous respectively.

The Gondwana sediments are deposited in a number of basins. The local stratigraphies which have been drawn up for the individual basins do not facilitate the establishment of a stratigraphy that is representative for the whole Gondwana System. The preservation of the Gondwana sediments is largely a result of faulting subsequent to the deposition of the beds concerned.

A vast area of the western and central parts of the Indian peninsula is covered by a series of plateau basalts - the Deccan traps - which have a thickness of at least $1,500 \mathrm{~m}$. The lavas were extruded during the Upper Cretaceous-Lower Eocene.

The northern part of the subcontinent of India is covered by Quaternary sediments of the Ganges and Indus plains. 


\section{SAMPLING IN THE FIELD}

Locally the sediments of the Gondwana Systems contain intercalations of reddish clays, shales and sandstones. From these red sediments, which may be suitable for a paleomagnetic research, oriented samples were collected at a few localities in the central Indian peninsula.

The sampling in the field was carried out with a portable diamond drill provided with a coring tube of $2.5 \mathrm{~cm}$ inner diameter. However, sometimes the Gondwana sediments are almost unconsolidated, and this prevents successful drilling; in that case oriented handsamples were taken.

Samples from the Upper Carboniferous Talchir Beds were taken on two localities (I and II in Fig.1). Only the laminated, unconsolidated red clays near Nagpur (locality I in Fig.1; site ITLA in Fig.2) did reveal a stable direction of magnetization (WENSINK and KLOOTWIJK, 1968).

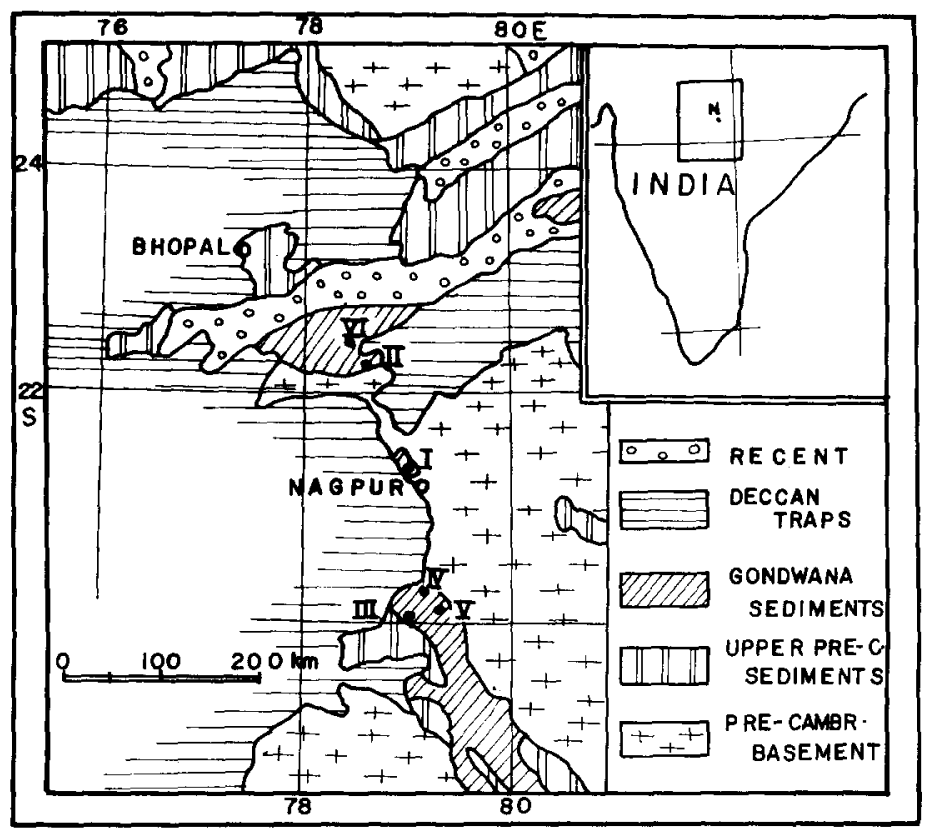

Fig.1. Geological map of central India with the sampling localities; locality $I$ corresponds to site ITL-A; II to ITL-B; $I I I$ to IWU-A, -B, -C, -D, -E, and -H; $I V$ to IML-A, and -B; $V$ to ITA-A, and -B; VI to IPC-B, -C, and -D.

In the northwestern part of the Godavary basin (localities III, IV, and V in Fig.1) sediments of the Lower Gondwana System are exposed in an almost flat area. Near Wun (locality III in Fig.1) outcrops of grey sandstones are found, which contain intercalations of red shales. The sediments near Wun are generally assigned to the Upper Permian Kamthi Beds (PASCOE, 1959). In six IWU (India 


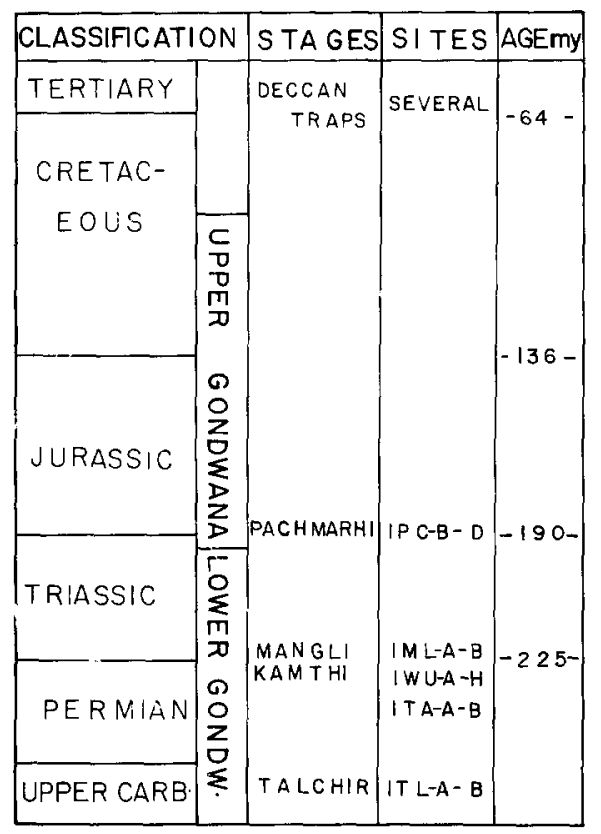

Fig.2. Schematic stratigraphical table of the Gondwana System from India indicating the Stages from which samples were collected for paleomagnetic research.

WUn) sites: IWU-A, -B, -C, -D, -E, and $-\mathrm{H}$, cores were drilled in these shales at three different places. At each site $12-15$ cores were taken. In the stratigraphical sequence the sites IWU-E and $-\mathrm{H}$ are situated about $70 \mathrm{~m}$ lower than the sites IWU-C ${ }^{1}$ and -D. The stratigraphical position of the remaining sites IWU-A and $-B$ is uncertain compared with that of the former four sites (see also p. 338).

Another two sites (ITA-A and -B; V in Fig.1) are located at Tadoba north of Chanda. In a series of sandstones and conglomerates an intercalation of red, sandy shales occurs, from which oriented cores were taken. The sites ITA-A and $-B$, furnished about fifteen cores each. These sediments may belong to the Kamthi Beds.

Near the village of Mangli, south of Nagpur, i.e., the type locality of the Lower Triassic Mangli Beds, oriented cores were drilled from two sites (IML-A and -B; IV in Fig.1) in red shales intercalated in white sandstones. At each of the sites IML-A and -B, fourteen cores were collected. Pebbles of these red shales were found within a conglomeratic layer that occurs later in the succession. Only at the outside are the shale pebbles somewhat decolourized. The presence of these pebbles in overlying conglomerates proves that the colouration of the shales is (almost) synsedimentary.

${ }_{1}$ Reliable paleomagnetic results of this site have not yet been obtained. 
The Gondwana sequence in the Satpura area consists of a slightly northward dipping series and contains both the Lower and a part of the Upper Gondwana System. Near Pachmarhi coarse sandstones and conglomerates are met with, which belong to the Upper Triassic-Lower Jurassic Pachmarhi Beds.

South of the village oriented cores were collected from three sites (IPC-B, $-C$, and -D; VI in Fig. 1) in reddish fine-grained sand- and siltstones which are intercalated in this succession. These three sites furnished about fifteen cores each.

ANALYSIS OF THE MAGNETIZATION

\section{General}

The samples collected in the field were investigated at the Paleomagnetic Laboratory of Utrecht University.

The handsamples were embedded in their oriented positions in cubes of paraffine with sides of $10 \mathrm{~cm}$. The cores were sawn into cylinders of $22 \mathrm{~mm}$ length. From some of the cores more than one cylinder could be obtained.

In order to obtain the intensity and the direction of the Natural Remanent Magnetization (N.R.M.) and its analysis all samples were measured on astatic magnetometers.

Demagnetization in alternating magnetic fields (a.c.)

The change of the total magnetization vector during the demagnetization procedure can best be illustrated in orthogonal projections in a rectangular axis system. This has the advantage that exact information can immediately be obtained about the change in both the intensity and the direction of magnetization of the specimen involved. The successive endpoints of the resultant magnetization vector, which represent the values obtained after the various steps of a progressive demagnetization, are described by a curve, the vector path. If this vector path is a straight line directed towards the centre of the coordinate system the magnetization decreases in intensity without changing its direction. This means that the magnetization consists of one single component (ZIJDER VELD, 1967). Clear examples of this procedure are illustrated in Fig. 10.

A few specimens from each site were progressively demagnetized in 10-15 successive steps in alternating magnetic fields (a.c. treatment). The maximal applied peak values were about 2,800 Oe. From each group of sites an example will be given below.

An example of the IWU sites from the Kamthi Beds near Wun is given in Fig.3. The specimens from these sites show an aberrant behaviour. During the progressive demagnetization in alternating fields above 500 Oe the intensity of magnetization of the specimen involved is steadily decreasing without showing a striking change in direction. The vector path follows a line which is not directed exactly towards the centre of the coordinate system. The deviation being small, 


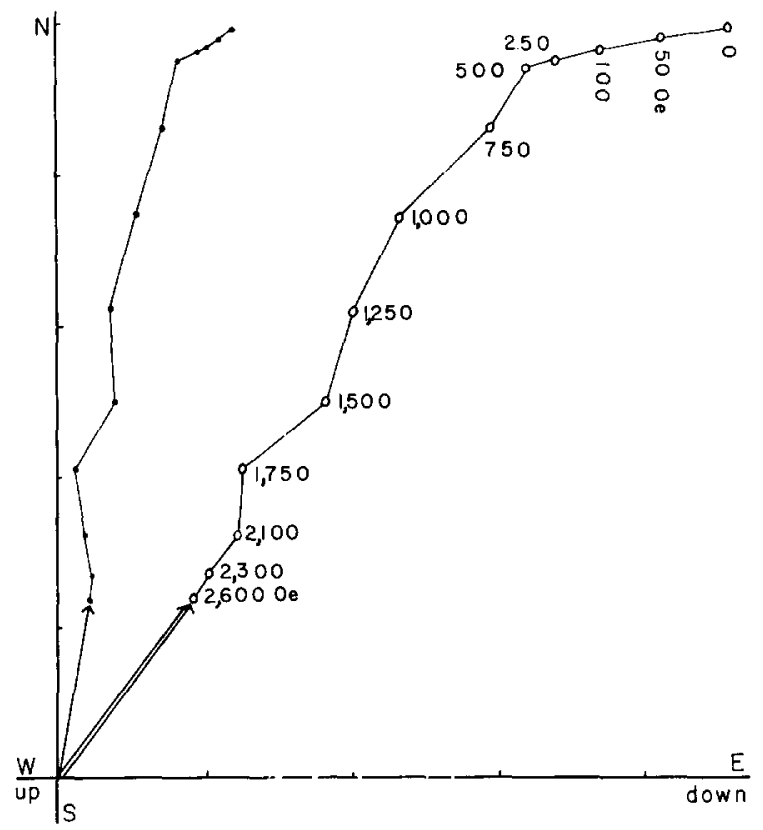

Fig.3. Diagram of the progressive demagnetization with alternating magnetic fields of specimen IWU-A2. The values indicated are Oersted peak values. Each unit on either axis is $1 \cdot 10^{-6}$ e.m.u. $/ \mathrm{cm}^{3}$. For these diagrams the following conventions are used:

The plotted points represent successive positions-in orthogonal projection-of the end of the resultant magnetization vector at each step during progressive demagnetization. Full circles are projections on the horizontal plane; open circles are projections on the vertical plane either north-south or east-west (in Fig. 3 the $N S$ ). Up and down indicates whether the northseeking direction is upward or downward, respectively. The demagnetization values applied are placed at the vertical projection only.

however, one is inclined to conclude that the magnetization consists of one single component only. The same observations were made with other specimens from IWU sites. However, thermal treatment of these specimens (not indicated on Fig.3), carried out after a.c. demagnetization, showed that a stable direction of magnetization had not been reached (see next part).

An example of the IML sites from the Mangli Beds near Mangli is given in Fig.4.

One observes that the direction of magnetization hardly changes by a.c. treatment, whereas thermal treatment with $600^{\circ} \mathrm{C}$ results in a considerable change in direction of magnetization.

For specimens from IWU and IML sites the decrease in the intensity of remanent magnetization with increasing strength of the alternating field demagnetization is illustrated in Fig.5. The specimens from IWU sites show a gradual decrease of the intensity of magnetization, whereas the intensity in magnetization of the specimen from site IML-A remains almost constant at a.c. treatment. 


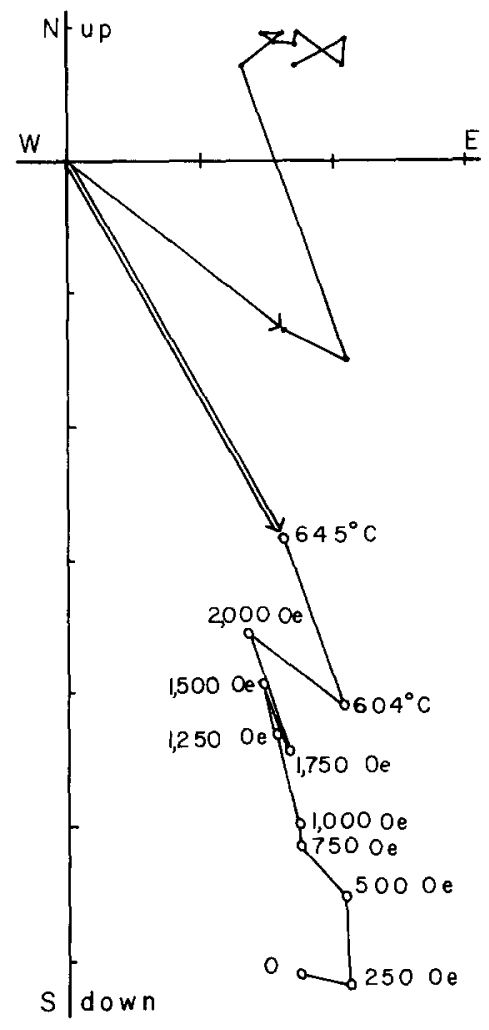

Fig.4. Demagnetization diagram of specimen IML-B1, showing a progressive a.c. demagnetization followed by heating in two steps. One unit is $5 \cdot 10^{-7}$ e.m.u. $/ \mathrm{cm}^{3}$. For further explanation see Fig.3.

Most specimens from the ITA and IPC sites, from the questionable Kamthi Beds near Tadoba and the Pachmarhi Beds near Pachmarhi, show a regular behaviour with a.c. treatment. In Fig.10A a small change in magnetic direction is observed until a.c. treatment at 1,000 Oe. From then onwards the vector path follows an almost straight line. Thermal treatment has further proved that in these specimens the N.R.M. is not composite.

\section{Thermal demagnetization}

For the thermal demagnetization of rock samples a furnace was used, constructed at the Paleomagnetic Laboratory by F. G. Mulder. The furnace is positioned in a set of three orthogonal pairs of field compensating square coils. The earth's magnetic field has been cancelled both on heating cycle and during cooling. During the experiments argon gas was brought into the oven.

Progressive thermal demagnetization in about eight steps has been carried 


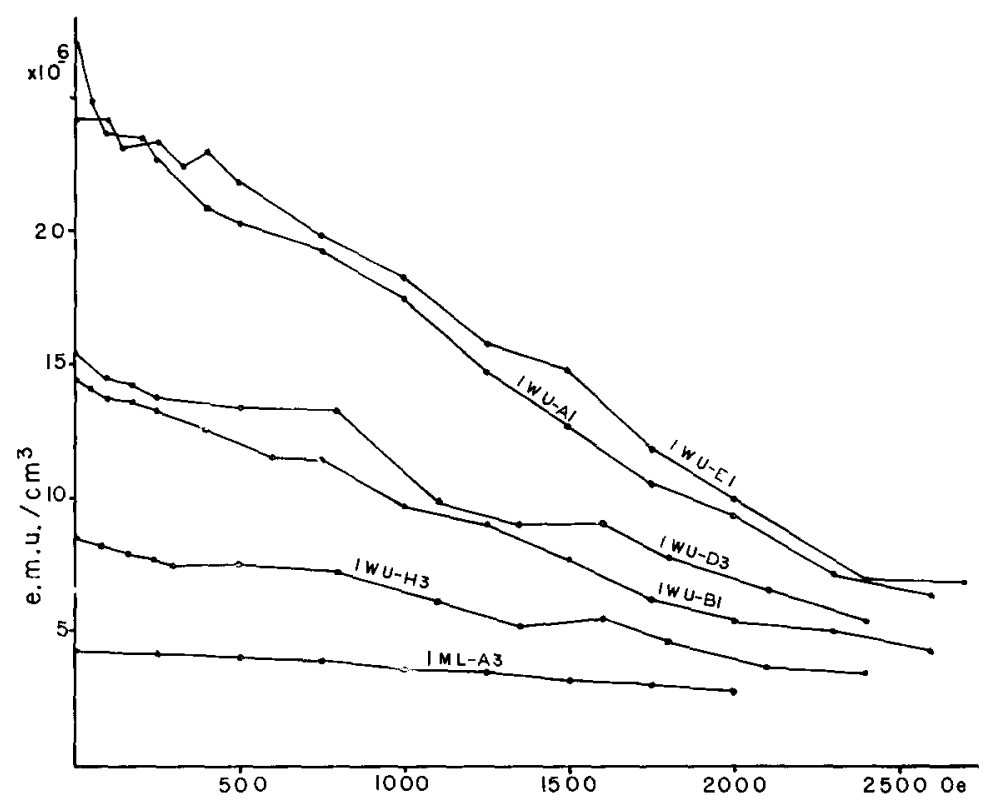

Fig.5. Curves showing the decrease in total intensity of natural remanent magnetization during a.c. demagnetization of specimens from IWU and IML sites.
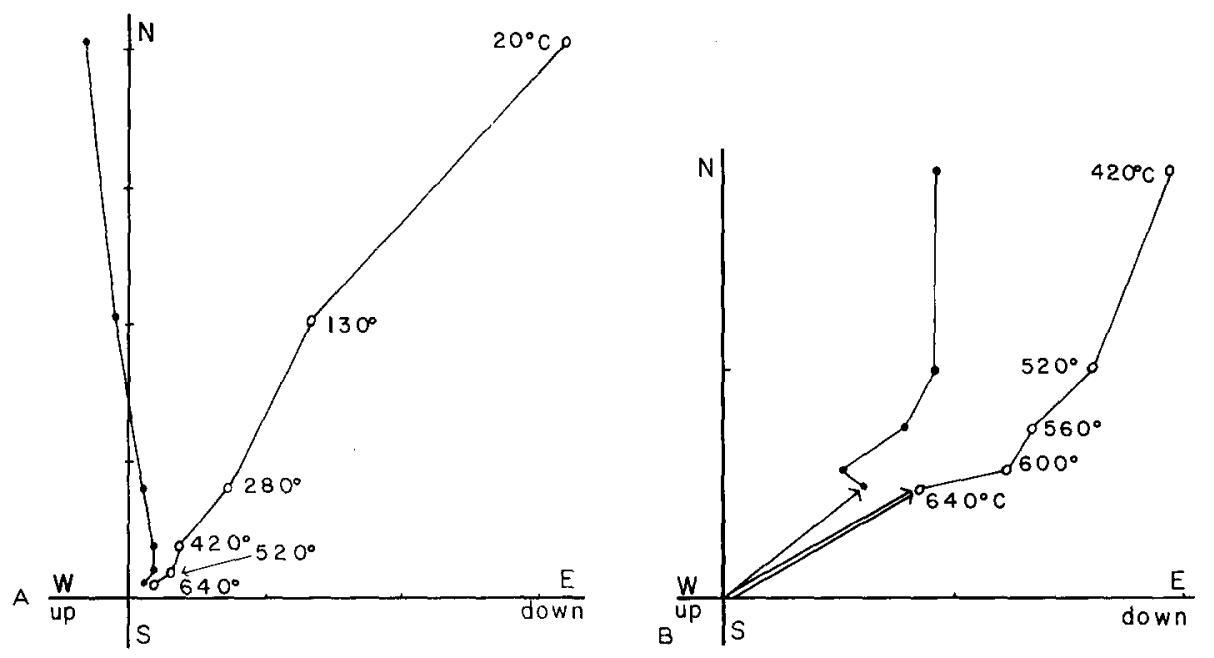

Fig.6. Demagnetization diagrams. A. Diagram of the thermal progressive demagnetization of specimen IWU-E2. One unit is $5 \cdot 10^{-6}$ e.m.u. $/ \mathrm{cm}^{3}$. B. Demagnetization diagram between $420^{\circ} \mathrm{C}$ and $640^{\circ} \mathrm{C}$ of same specimen. One unit is $1 \cdot 10^{-6}$ e.m.u. $/ \mathrm{cm}^{3}$. For further explanation see Fig.3. 
out with 4-6 specimens from each site. The remaining specimens were heated at 2-4 different temperatures.

Progressive thermal treatment of specimens from the IWU sites results in a rapid decrease in intensity of magnetization already at temperatures up to $300^{\circ} \mathrm{C}$ (Fig.7). On the application of higher temperatures the intensities of magnetization decrease more gradually. A demagnetization diagram of a specimen from site IWU-E 2 is given in Fig.6A, where a gradual change in the resultant direction of magnetization is observed. As only about $5 \%$ of the original N.R.M. is left after heating at $420^{\circ} \mathrm{C}$, the behaviour of the magnetization vector on the application of still higher temperatures is presented on a larger scale in Fig.6B. It appears that from $520^{\circ} \mathrm{C}$ onwards the direction of magnetization no longer changes significantly. However, the vector path does not follow a completely straight line, because at the very low intensities of magnetization left after thermal treatment, the error in the measurements is relatively large. ${ }^{1}$

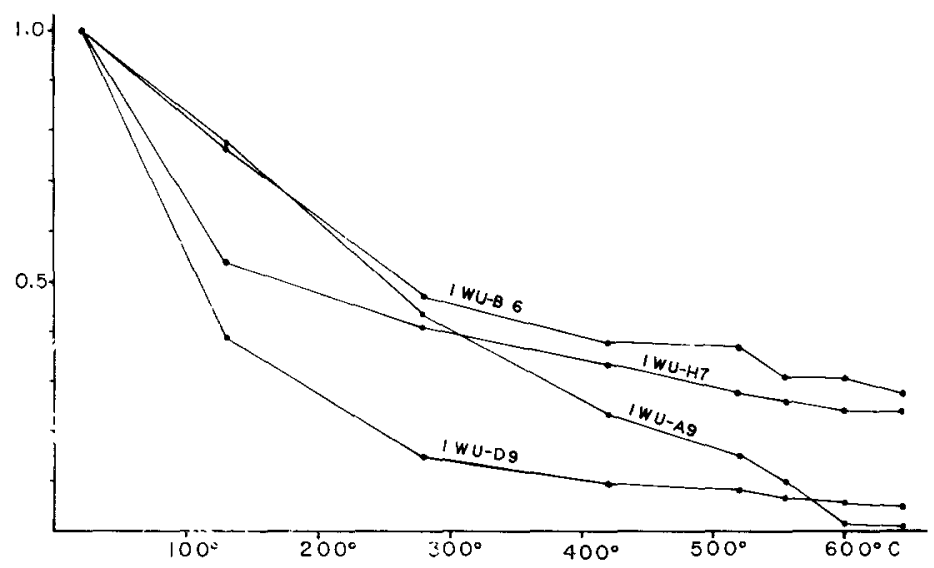

Fig.7. Curves showing the normalized intensities of natural remanent magnetization from pecimens of IWU sites during thermal demagnetization.

Many progressively heated specimens show this effect (see also Fig.8). Apart from these measuring errors the vector path is directed towards the centre of the coordinate system. One may, therefore, conclude that the thermal treatment of the IWU specimens reveals that their N.R.M. is composite whilst the remaining magnetization after heating above $500^{\circ} \mathrm{C}$ probably consists of one single component.

The specimens from the IML sites do not show a strong drop in intensity of magnetization during progressive heating. However, the direction of magnetization strongly changes after thermal treatment. Fig. 9 illustrates that there is a drop in

1 The effect of the errors in the measurements on a particular specimen can be reduced by computing the mean direction of magnetization from the values obtained after heating at successive temperatures above $500^{\circ} \mathrm{C}$. This procedure has been applied to almost all specimens. 


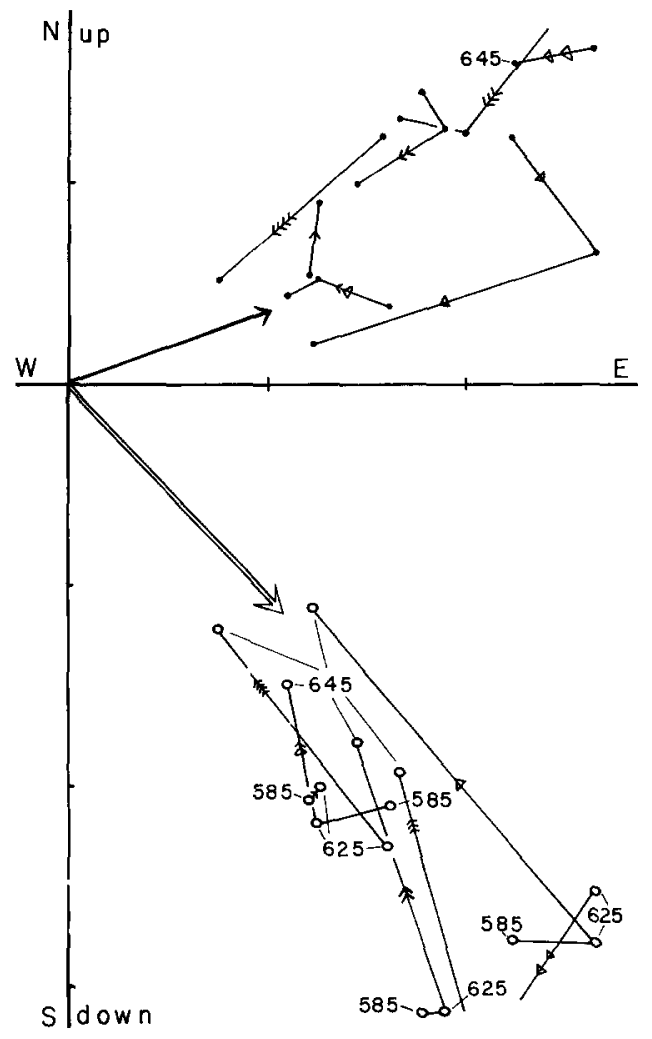

Fig.8. Diagrams of partly thermal demagnetizations of a number of specimens from site IWU-E, mainly between $585^{\circ} \mathrm{C}$ and $645^{\circ} \mathrm{C}$ : the individual specimens show a scatter in directions of magnetization as a result of errors in the measurements. One unit is $5 \cdot 10^{-7}$ e.m.u. $/ \mathrm{cm}^{3}$. For further explanation see Fig.3.

intensity of magnetization at heating up to $200^{\circ} \mathrm{C}$; from then onwards no change in intensity is observed till $500^{\circ} \mathrm{C}$; above $500^{\circ} \mathrm{C}$ the intensity of magnetization generally increases, after which the specimens from the IML sites contain at least two thermally soft components of magnetization both of which have been eliminated at about $500^{\circ} \mathrm{C}$. From Fig. 4 it can be derived that a.c. treatment does not change the direction of magnetization of a specimen from site IML-B; however, heating at $600^{\circ} \mathrm{C}$ carried out afterwards resulted in a considerable clockwise change of direction of magnetization.

In general, specimens from the IPC and ITA sites do not show an important change in direction of magnetization at heating, as is demonstrated in the example of Fig.10B. In Fig.10A it is illustrated that after progressive a.c. demagnetization up to 2,750 Oe peak value, heating at about $600^{\circ} \mathrm{C}$ only results in a decrease in intensity of magnetization without showing a change in direction. In Fig.11 the 


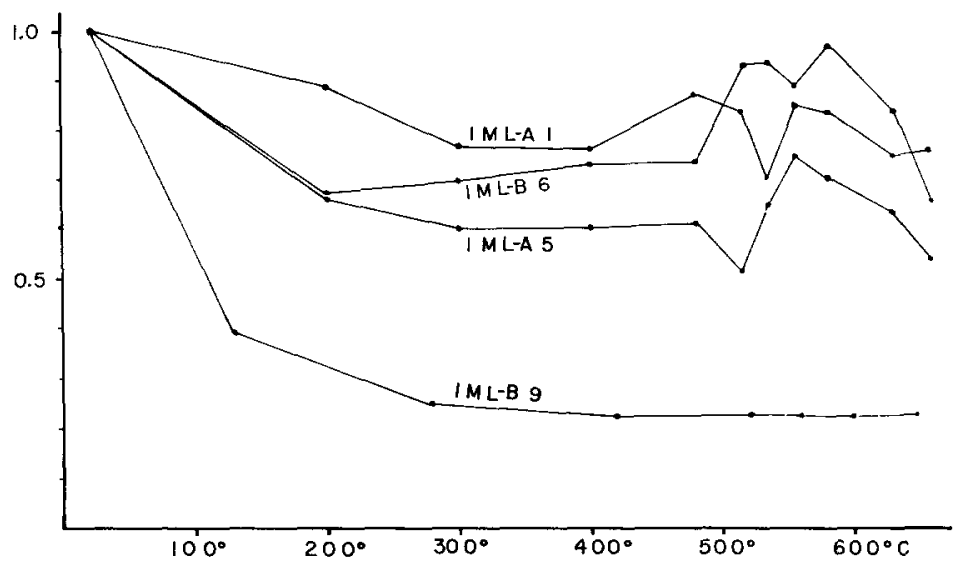

Fig.9. Curves showing the normalized intensities of natural remanent magnetization of specimens from IML sites during thermal treatment. The intensities decrease to about $300^{\circ} \mathrm{C}$; remain constant up to $500^{\circ} \mathrm{C}$ and then mostly increase before the final decrease is observed. This behaviour may be attributed to at least two secondary components of magnetization, which are removed at about $300^{\circ} \mathrm{C}$ and $500^{\circ} \mathrm{C}$, respectively.
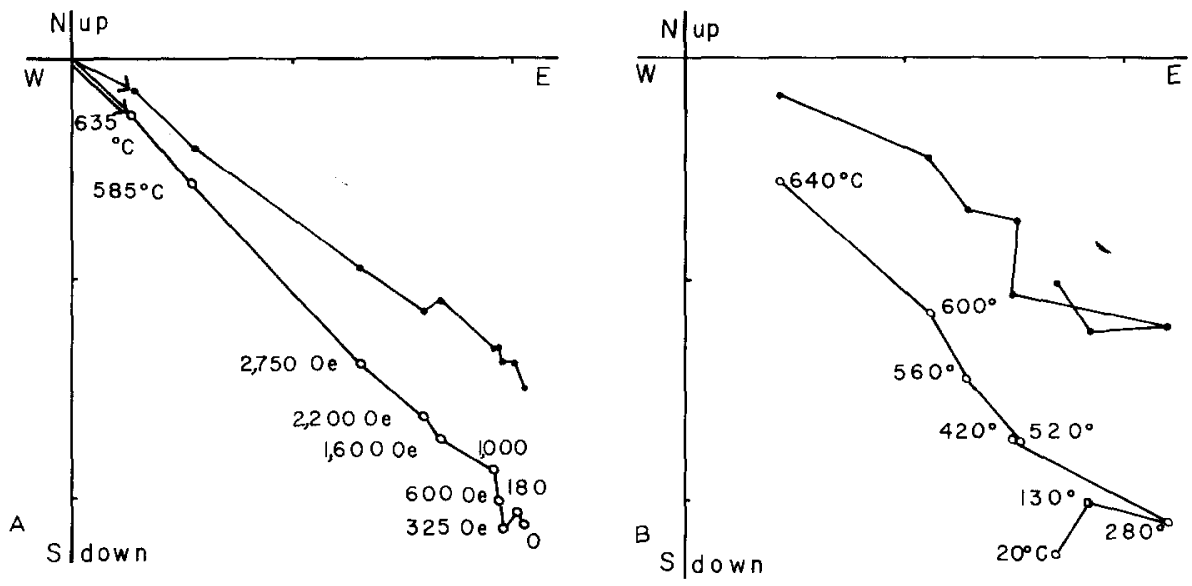

Fig.10. Demagnetization diagrams. A. Demagnetization diagram of specimen IPC-C2, showing a progressive a.c. treatment followed by a thermal treatment in two steps. One unit is $5 \cdot 10^{-6}$ e.m.u. $/ \mathrm{cm}^{3}$. B. Progressive thermal demagnetization diagram of specimen IPC-D6. One unit is $1 \cdot 10^{-6}$ e.m.u. $/ \mathrm{cm}^{3}$. For further explanation see Fig.3.

gradual decrease of intensity of magnetization with progressive heating is presented for a number of specimens from IPC sites.

\section{Comparison of a.c. demagnetization with thermal demagnetization}

After the extensive alternating-field and heating demagnetization experiments 


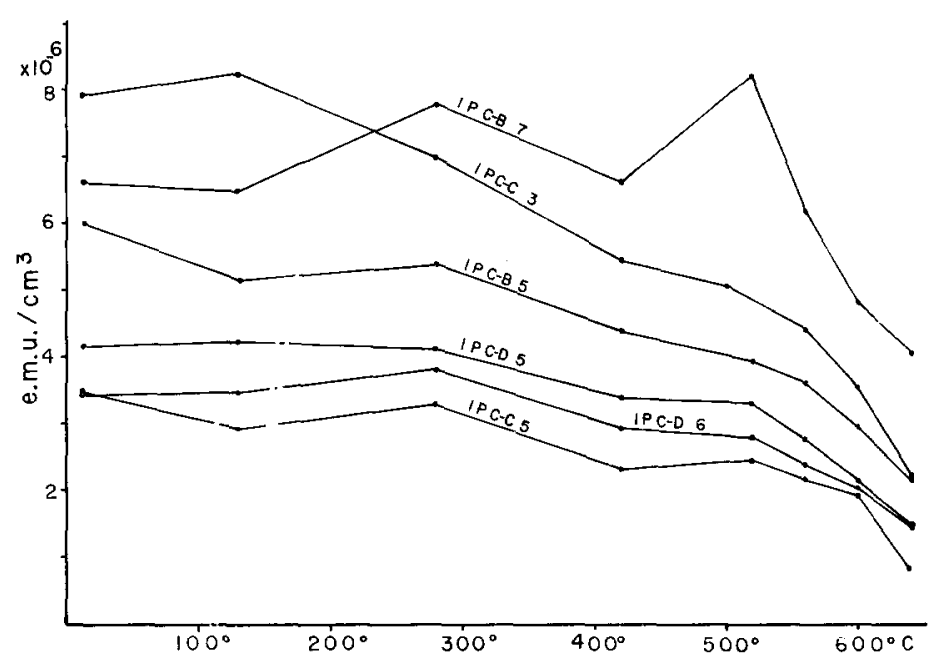

Fig.11. Curves showing the decrease in total intensity of natural remanent magnetization of specimens from IPC sites during thermal demagnetization.

it is possible to make a division of the investigated material based on paleomagnetic properties.

Three different groups can be distinguished to which belong the specimens from the IWU sites (I), the specimens from the IML sites (II), and the specimens from the IPC and ITA sites (III), respectively.

The specimens of group I have a composite N.R.M. from which the secondary component(s) cannot be removed in alternating magnetic fields. The secondary component(s) have very strong coercive forces, but relatively low blocking temperatures. The decrease in intensity of magnetization during a.c. treatment in stronger fields proceeds gradually (Fig.5) without any indication of eliminating the secondary component(s). These were, however, found at heating carried out after a.c. treatment which suggests that during a.c. both the primary and the secondary component(s) of magnetization are affected. Thermal treatment shows a rapid decrease in intensity after heating up to $300^{\circ} \mathrm{C}$ (Fig.7) which coincides with a clockwise change in direction (Fig.6). The main secondary component(s) with strong coercive forces must have been removed then, but the specimens are not completely cleaned until heating at over $500^{\circ} \mathrm{C}$ (Fig.6B).

At demagnetization the specimens of group II show a magnetic behaviour which resembles that of the specimens of group I. The secondary component(s) of magnetization cannot be removed with a.c. treatment either (Fig.4). In general, the N.R.M. intensities are lower than those of group I, but the decrease in intensity during a.c. demagnetization is very slight (see IML-A3 in Fig.5). There is also a slight decrease in intensity when heating up to about $300^{\circ} \mathrm{C}$, mostly followed by an increase again at $500^{\circ} \mathrm{C}$ (Fig.9). However, the direction of magnetization changes, 
which does not occur at all during a.c. treatment (Fig.4). At least two secondary components can be distinguished both of which are removed at about $500^{\circ} \mathrm{C}$ (Fig.9). The greater part of the specimens then seems to be "clean".

The specimens of group III are characterized by the occurrence of secondary magnetic component(s) with low coercive forces, which can be easily removed with alternating magnetic fields. The results obtained after thermal treatment of this material are generally consistent with those received from a.c. treatment (Fig.10).

\section{DIRECTIONS OF MAGNETIZATION}

From the foregoing it is learned that from the samples studied, the majority does not reveal the primary magnetization by a.c. treatment. Since thermal treatment appeared to be more successful for these red beds, only the results are used of those specimens that have been thermally demagnetized.

In a number of stereograms the magnetic directions of the individual specimens from a number of sites are plotted both before and after demagnetization. The stereograms of Fig.12 and Fig.13 show the directions of magneti-
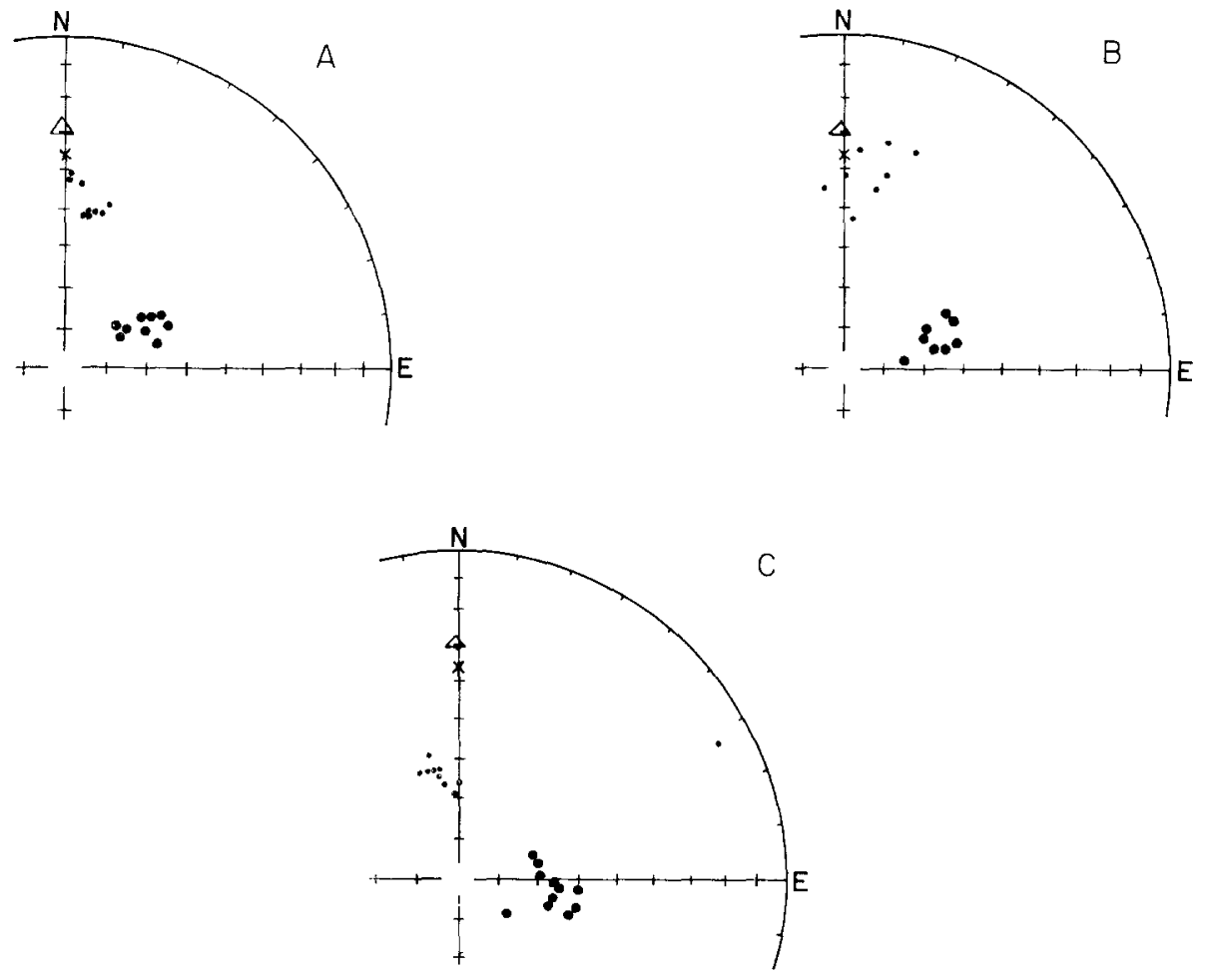

Fig. 12. For legend, see p. 336. 

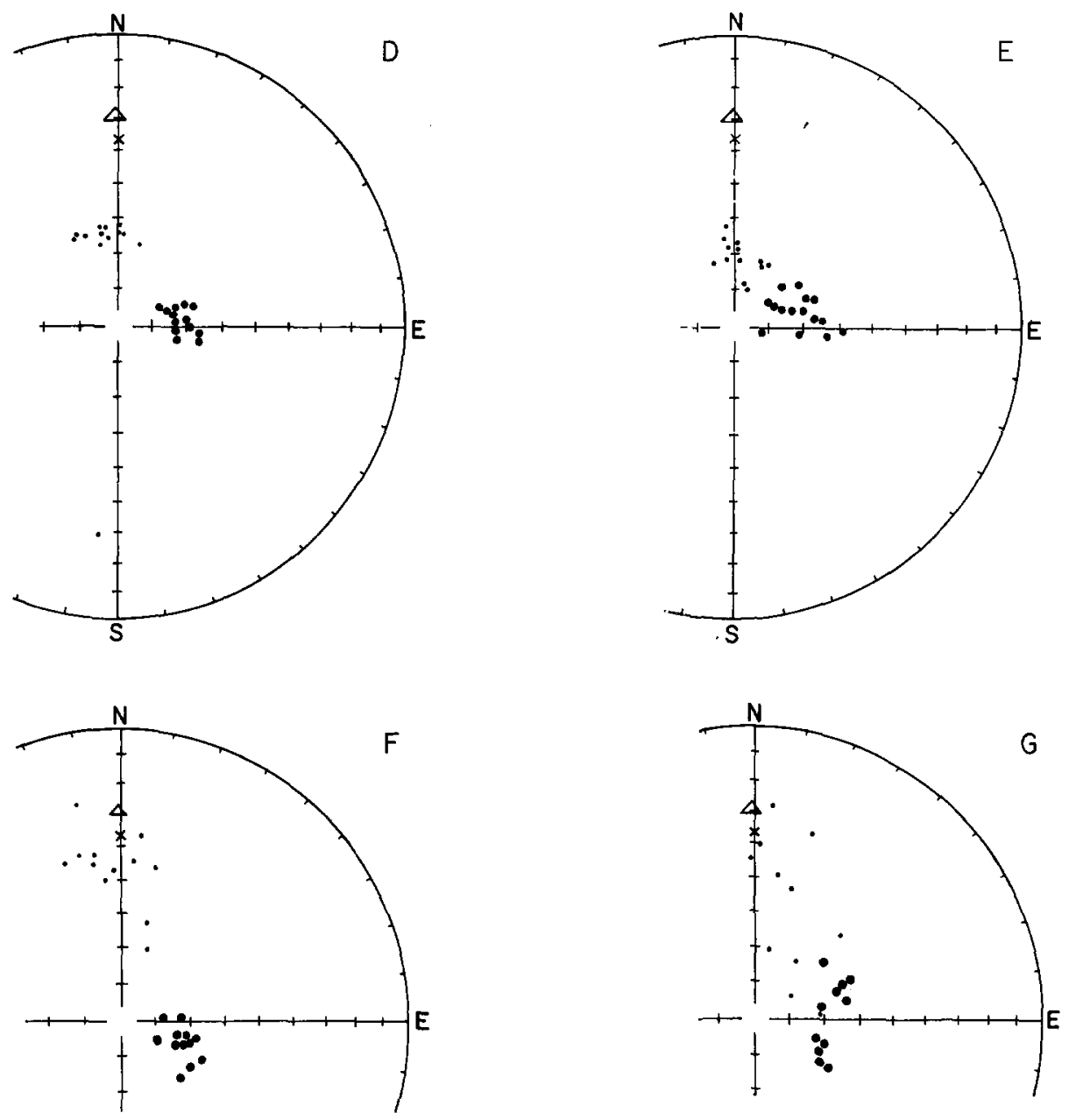

Fig.12. Stereograms showing the directions of the magnetic vectors of specimens from IWU sites and IML sites after tectonic correction, both from initial measurements (small circles) and after thermal treatment (full circles). Full circles indicate that $\mathrm{N}$-seeking poles are pointing downward; open circles denote that $\mathrm{N}$-seeking poles are pointing upward. Triangle is the direction of the present-day geomagnetic field at Nagpur; cross is the local direction of the axial earthmagnetic dipole field.

A. site IWU-A; B. site IWU-B; C. site IWU-D; D. site IWU-E; E. site IWU-H; F. site IML-A; G. site IML-B.

zation of the specimens from the IWU and IML sites and site IPC-B. These projections show that the N.R.M. directions obtained by initial measurements of specimens from the IWU and IML sites-group I and group II respectivelycorrespond to some extent with the direction of the earth's present field in India. The initial N.R.M. directions of the remaining sites, however,-group IIIstrongly deviate already from the present direction. 

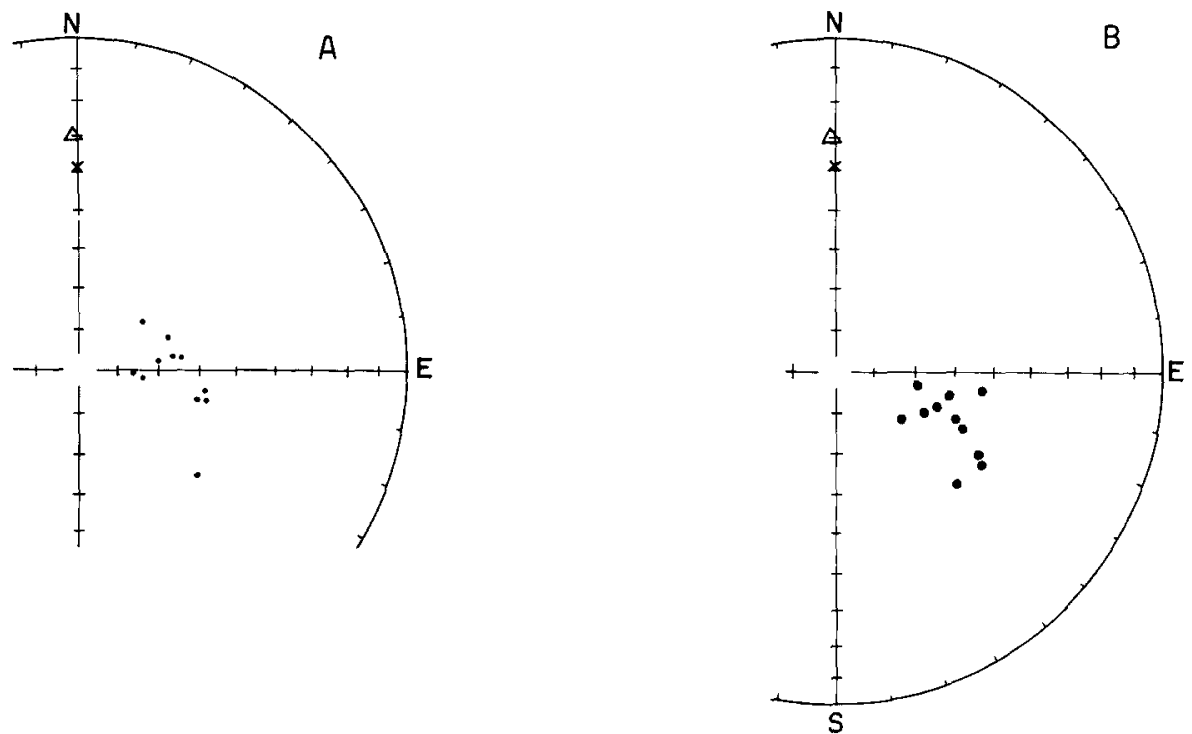

Fig.13. Stereograms showing the directions of the magnetic vectors of specimens from site IPC-B after tectonic correction. H. Initially measured N.R.M.; J. After thermal treatment. For further explanation see Fig.12.

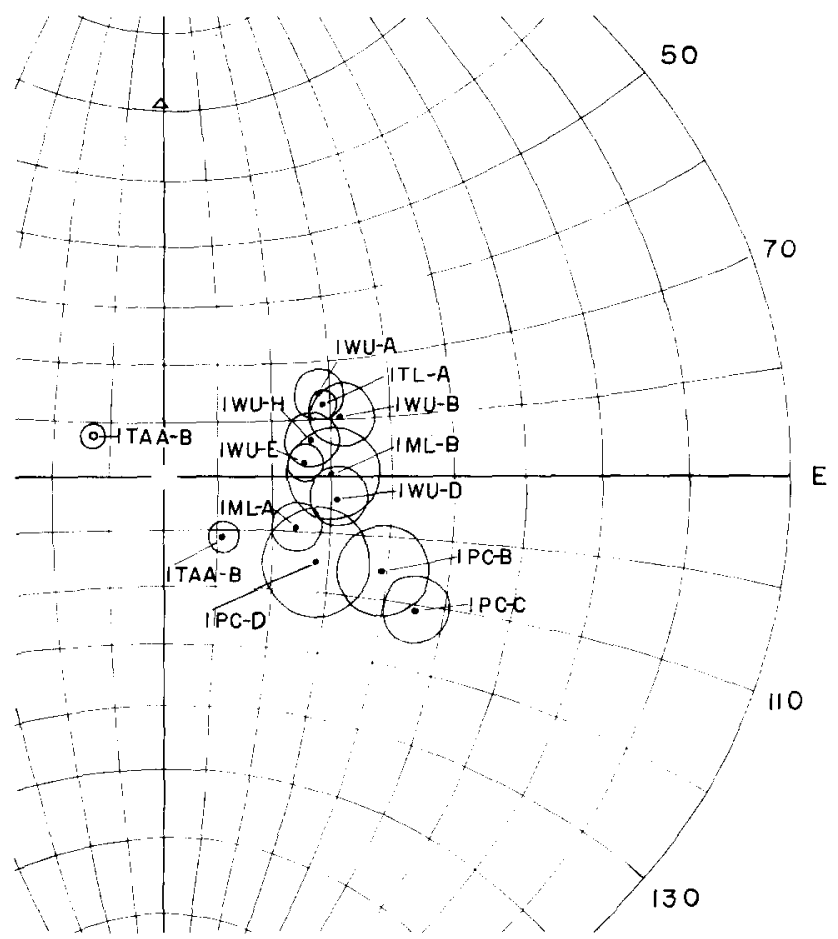

Fig.14. Part of a stereogram showing the mean directions of magnetization after thermal treatment of twelve Gondwana sites with the cones of $95 \%$ confidence. All dots denote $\mathrm{N}$-seeking poles pointing downwards; open circle denotes $\mathrm{N}$-seeking poles pointing upwards. Triangle is the direction of the present-day geomagnetic field at Nagpur. 


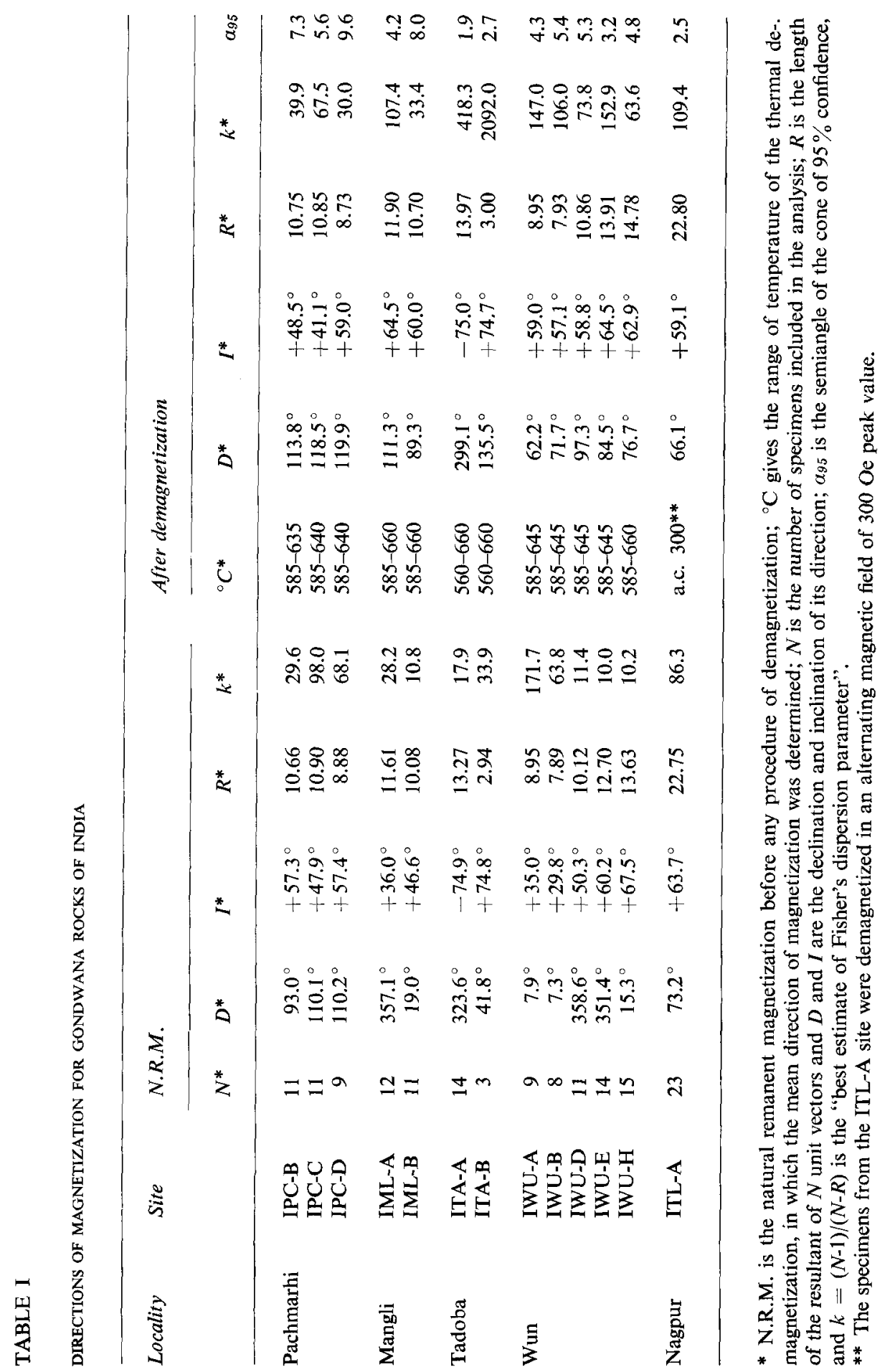

Palaeogeography, Palaeoclimatol., Palaeoecol., 5 (1968) 323-343 
For each site the mean directions of magnetization were computed from the results of the individual specimens both before and after demagnetization. They are listed in Table I, where the results obtained from the Talchir sediments (site ITL-A) are given too.

Usually, when in a stratigraphical series the number of sites is sufficiently large, the mean direction of magnetization is computed by combining the site directions. In this paper, however, the number of sites is too small for this kind of

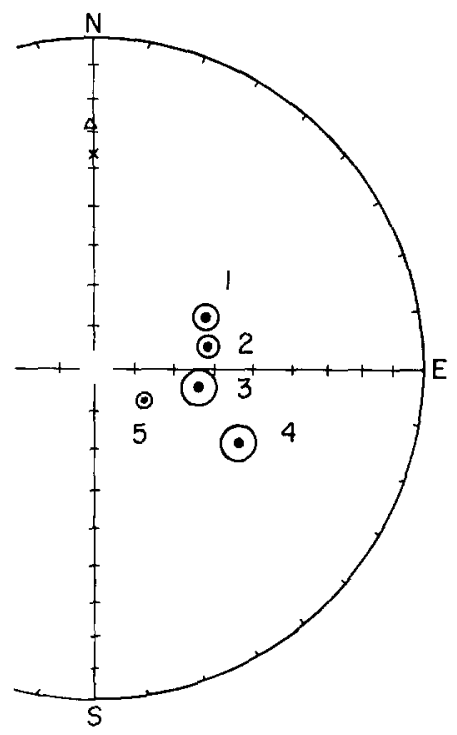

Fig.15. Part of a stereogram (equal area projection) showing the mean directions of magnetization of five groups of sites derived from the total number of individual specimens of each group of sites with their circles of confidence. Numbers 1-5 represent the ITL site, the IWU sites, the IML sites, the IPC sites, and the ITA sites, respectively. All directions have $\mathrm{N}$-seeking poles pointing downwards.

TABLE II

MEAN DIRECTIONS OF MAGNETIZATION AFTER THERMAL TREATMENT DERIVED FROM THE TOTAL NUMBER OF SPECIMENS FROM COMBINED SITES ${ }^{1}$

\begin{tabular}{lrrrrrr}
\hline Sites & $N$ & Decl. & Incl. & $R$ & $k$ & $\alpha_{95}$ \\
\hline IPC B-D & 31 & $117.2^{\circ}$ & $+48.9^{\circ}$ & 30.08 & 32.8 & $4.6^{\circ}$ \\
IML A-B & 23 & $100.1^{\circ}$ & $+62.8^{\circ}$ & 22.49 & 43.3 & $4.6^{\circ}$ \\
ITA A-B & 17 & $122.0^{\circ}$ & $+75.1^{\circ}$ & 16.96 & 411.1 & $1.8^{\circ}$ \\
IWU A-H & 57 & $79.4^{\circ}$ & $+61.6^{\circ}$ & 56.11 & 62.8 & $2.4^{\circ}$ \\
\hline
\end{tabular}

1 For explanation of symbols see Table I. 
treatment. Therefore, in a particular stratigraphical series, unit weight was given to each specimen, which could be done because the specimens are regularly distributed throughout the stratigraphical series. The results are listed in Table II; they are also given in Fig.15. From the projections of Fig.14 and 15 combined with the column of Fig. 2 it is clear that the direction of magnetization rotates from east-northeast in the Upper Carboniferous towards almost southeast in Upper Triassic times.

POLE POSITIONS AND PALEOLATITUDES

From the mean directions of magnetization of specimens from sites per- taining to the same stratigraphical unit, the virtual geomagnetic pole positions were calculated (Table III).

TABLE III

POLE POSITIONS CALCULATED FROM THE MEAN DIRECTIONS OF MAGNETIZATION (TABLE II)

\begin{tabular}{|c|c|c|c|c|c|c|c|}
\hline \multicolumn{3}{|l|}{ Site position } & \multicolumn{5}{|c|}{ Site pole } \\
\hline sites & lat. $N$ & long. $E$ & lat. & long. $W$ & $\delta \mathrm{p}^{*}$ & $\delta \mathrm{m}^{*}$ & $\lambda^{*}$ \\
\hline IPC B-D & $22.44^{\circ}$ & $78.44^{\circ}$ & $10.1^{\circ} \mathrm{N}$ & $49.9^{\circ}$ & $4.0^{\circ}$ & $6.1^{\circ}$ & $29.8^{\circ} \mathrm{S}$ \\
\hline IML A-B & $20.45^{\circ}$ & $79.00^{\circ}$ & $7.3^{\circ} \mathrm{S}$ & $55.7^{\circ}$ & $5.7^{\circ}$ & $7.3^{\circ}$ & $44.2^{\circ} \mathrm{S}$ \\
\hline ITA A-B & $20.22^{\circ}$ & $79.28^{\circ}$ & $4.1^{\circ} \mathrm{N}$ & $77.2^{\circ}$ & $2.9^{\circ}$ & $3.2^{\circ}$ & $62.0^{\circ} \mathrm{S}$ \\
\hline IWU A-H & $20.05^{\circ}$ & $78.95^{\circ}$ & $21.0^{\circ} \mathrm{S}$ & $50.4^{\circ}$ & $2.8^{\circ}$ & $3.7^{\circ}$ & $42.7^{\circ} \mathrm{S}$ \\
\hline
\end{tabular}

* $\delta p$ and $\delta m$ are the semiaxes of the oval of $95 \%$ confidence for the mean pole position; $\lambda$ is the paleolatitude of the site position.

The virtual geomagnetic poles are indicated on a map showing Middle and South America and parts of the adjoining oceans (Fig.16).

Besides the poles derived from the paleomagnetic data presented in this paper, a few other pole positions are indicated on this map (no. 4, 7, 8, and 9). Position no. 4 is derived from Kamthi Beds of the Godavary Valley (Verma et al., 1968). Position no. 7 is the locality of the virtual pole derived from the Jurassic Rajmahal and Sylhet traps (Clegg et al., 1958; Athavale et al., 1963). Position no. 8 is obtained from the Middle Cretaceous Tirupati Sandstones of the Godavary Valley (Verma et al., 1967). Position no. 9 is a virtual geomagnetic pole position computed from the mean direction of magnetization (after a.c. treatment) of the Deccan traps and which was derived from a compilation of our unpublished data of 34 basalt flows (about 200 specimens) from the western Ghats. This position is not significantly different from the values published earlier (DEUTSCH et al., 1959; IRVING, 1964). 


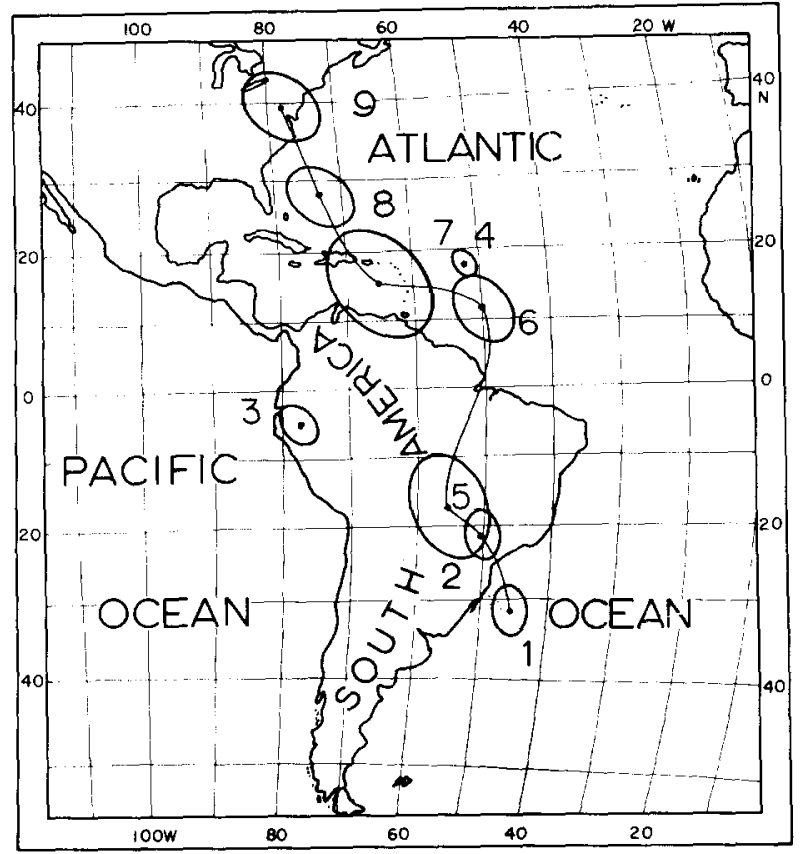

Fig.16. Map of part of the Western Hemisphere showing the virtual geomagnetic poles derived from various groups of sites: Upper Carboniferous Talchir Beds near Nagpur (I); Upper Permian Kamthi Beds near Wun (2); Lower Triassic Mangli Beds near Mangli (3); Upper TriassicLower Jurassic Pachmarhi Beds near Pachmarhi (4); Kamthi Beds (?) near Tadoba (5); Upper Permian Kamthi Beds in the Middle Godavary valley (6); Jurassic basalts from the Rajmahal and Sylhet traps (7); Middle Cretaceous Tirupati sandstones in the Lower Godavary valley (8); Upper Cretaceous to Lower Eocene basalts from the Deccan traps in the western Ghats (9).

A line is drawn through the successive pole positions, which represents the apparent Polar Wandering Curve for the Indian subcontinent from the Upper Carboniferous till the Eocene. The position no. 5 obtained from the ITA-series has an aberrant position. The sites in this series are situated near the boundary of the Gondwana Basin with the Late Precambrian, unmetamorphosed red shales and sandstones of the Vindhyan System. Therefore, the possibility of an Upper Precambrian age of the ITA-series must be considered. Nor does position no. 6 fit in well with this pattern, which may be due to an incompleteness of the demagnetization procedures.

The paleolatitude $(\lambda)$ is calculated from the dipole equation:

$$
\tan \lambda=1 / 2 \tan I
$$

where $I$ is the inclination of magnetization. The paleolatitudes for India were computed for five different periods, e.g., the Upper Carboniferous; the Upper Permian; the Lower Triassic; the Upper Triassic; and the Upper Cretaceous. The inferred positions of the Indian peninsula are put on a map of the Indian Ocean 
(Fig.17). Here, the longitudinal shift of India takes place along its present $80^{\circ} \mathrm{E}$ meridian. The successive positions based on the paleomagnetic results show that the northward directed shift of India is very small from Upper Paleozoic through Mesozoic times. However, a considerable counter-clockwise rotation of about $90^{\circ}$ has taken place.

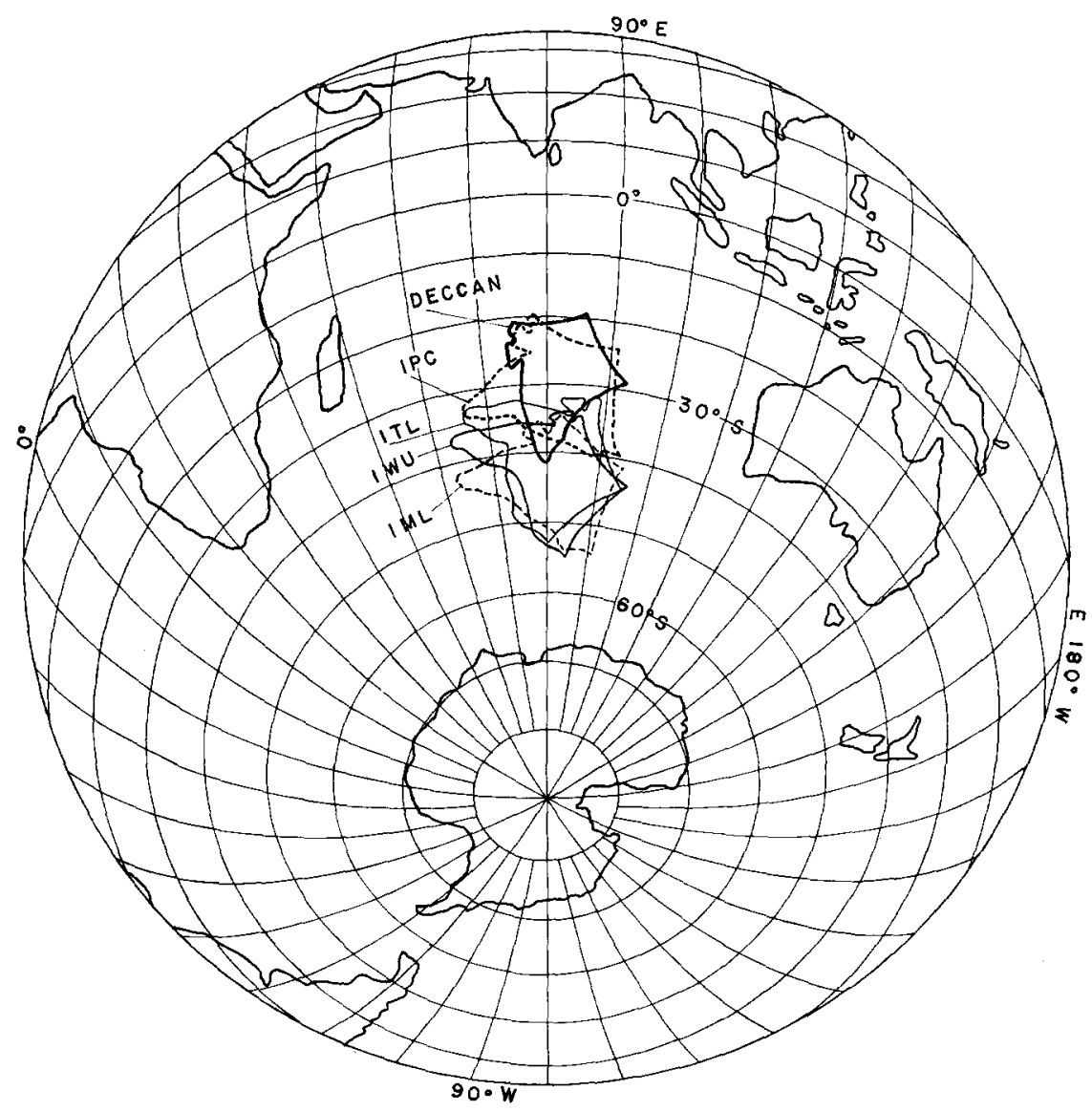

Fig.17. Map of the Indian Ocean area showing the latitudinal positions of the Indian subcontinent during the Upper Carboniferous and the Mesozoic. Positions are derived from paleomagnetic data of ITL site (Upper Carboniferous); of IWU sites (Upper Permian); of IML sites (Lower Triassic); of IPC sites (Upper Triassic-Lower Jurassic); and of sites from the Deccan traps (Upper Cretaceous-Lower Eocene).

\section{ACKNOWLEDGEMENTS}

The author is most obliged to Professor M. G. Rutten and J. Veldkamp for their interest in this study and their critical remarks. 
Drs. J. D. A. Zijderveld has kindly given advice during the preparation of this work. Many thanks are also due to Mr. C. T. Klootwijk, who assisted the author during the fieldwork.

\section{REFERENCES}

Athavale, R. N., Radhakrishamurty, C. and Sahasrabudhe, P. W., 1963. Paleomagnetism of some Indian rocks. Geophys. J., 7: 304-313.

ClegG, J. A., Radhakrishamurty, C. and SahasRabudhe, P. W., 1958. Remanent magnetization of the Rajmahal traps in northeastern India. Nature, 181: 830-831.

Deutsch, E. R., Radhakrishamurty, C. and Sahasrabudhe, P. W., 1959. Paleomagnetism of the Deccan traps. Ann. Geophys., 15: 39-59.

Irving, E., 1964. Paleomagnetism. Wiley, New York, N.Y., 399 pp.

KrishnAN, M. S., 1960. Geology of India and Burma, 4th ed. Higginbotham, Madras, 604 pp.

PASCOE, E., 1959. A manual of the geology of India and Burma, 2. Geol. Surv. India, Misc. Publ.,: $485-1343$.

Verma, R. K. and Bhalla, M. S., 1968. Paleomagnetism of Kamthi sandstones of Upper Permian age from Godavary Valley, India. J. Geophys. Res., 73: 703-709.

Verma, R. K. and Pullaiah, G., 1967. Paleomagnetism of Tirupati sandstones from Godavary Valley, India. Earth Planetary Sci. Letters, 2: 310-316.

WADIA, D. N., 1953. Geology of India, 3rd ed. Macmillan, London, $532 \mathrm{pp}$.

Wensink, H. and KLOOTwIJK, C. T., 1968. The paleomagnetism of the Talchir Series of the Lower Gondwana System, central India. Earth Planetary Sci. Letters, 4: 191-196.

Zijderveld, J. D. A., 1967. A.C. demagnetization of rocks: analysis of results. In: D. W. ColLINSON, K. M. CREER and S. K. RUNCORN (Editors), Methods in Palaeomagnetism. Elsevier, Amsterdam, pp.254-286. 